\title{
Visual design. A step towards multicultural health care
}

\author{
Juliana Alvarez, Ms.S ${ }^{a}$
}

\begin{abstract}
Standing at the crossroads of anthropology, communication, industrial design and new technology theories, this article describes the communication challenges posed during hospital emergencies resulting from linguistic and cultural differences between health care professionals and patients. In order to overcome communication barriers, the proposal of a visual solution was analyzed. Likewise, the problem was studied based on the concepts of perception, comprehension, interpretation and graphic representation according to visual culture and semiotics theories. Onehundred and fifty images showing symptoms were analyzed in order to identify a pluricultural iconographic code. Results enabled to develop a list of design criteria and create the application: "My Symptoms Translator" as an option to overcome verbal language barriers and cultural differences.

Keywords:health, symptoms, emergencydepartment, visual communication, semiotics.
\end{abstract}

http:/ /dx.doi.org/10.5546/aap.2014.eng.33

\section{INTRODUCTION}

Intercultural communication in the health field has been studied through several conceptual approaches or specific perspectives, such as anthropological, sociological, philosophical, psychological, and even medical disciplines. ${ }^{1}$ Very few researchers have considered intercultural communication from the perspective of design.

This is a pretty novel discipline which interestingly offers researchers the freedom to develop their own methodology based on other, already established, approaches. The objective of any design project is to develop

a. IDE3S Inc. Queen Mary, Montreal, Québec, Canadá.

E-mail address: contact@ide3s.com

Conflict of interest: None.

Received: 06-17-2013 Accepted: 08-12-2013 lead to the conceptualization of a solution. In order to implement this inventory, research is usually conducted in several stages: study of the environment and its actors; proposal of a solution; analysis of technical, functional, aesthetic, and ergonomic criteria, among others; creation of a solution; and lastly, the implementation in the setting and study of applicability.

\section{The study}

Considering the changes experienced by present societies as a result of immigration, ${ }^{\text {I four years }}$ ago we started a research project in design together with a group of anthropologists and physicians from Sainte-Justine University Hospital Center, University of Montreal. This article describes the communication challenges encountered by health care professionals in their everyday practice.

Given the highly challenging context of Emergency Rooms (ER), this research focused on the study of this specific environment. The study was divided into two parts: at first, the environment of the ER of Sainte-Justine Hospital and its actors (nurses, doctors, patients and family members) were described in order to identify relevant factors and the design criteria to be included in the proposal of a solution; then, the design methodology and theories of visual culture were implemented and a

I. Thousands of people arrive in the province of Quebec every year (51 $737 \mathrm{in} 2011$; MCCI). Montreal is the most important point of arrival in the province, and houses $90 \%$ of immigrants. As per Statistic Quebec (2006), of the 1800000 Montreal inhabitants, 27\% were born abroad and come from more than 90 different countries. In 2004,39\% of children seen at the emergency department of SainteJustine Hospital spoke neither French nor English as their mother tongue. The most common languages were: $8 \%$ Arabic, $6 \%$ Spanish, $4 \%$ Vietnamese, 2\% Bengali, 2\% Tamil, etc. In addition, $44 \%$ of fathers and $43 \%$ of mothers were born outside Canada. ${ }^{1}$ 
multicultural visual language was proposed, from its conception to its creation. The implementation of the communication system is still under study and will be the subject of a future article.

\section{Development}

Current social reality

Alterity ${ }^{\mathrm{II}}$ represents a great wealth for society, although it is necessary to consider the impact of multiethnic dynamics on the social and cultural life of individuals, and consequently, on how they communicate. ${ }^{2-3}$ The large number of changes in social and political structures have led professionals, who base most of their interventions on interpersonal relationships, to question their everyday practice. In the health field, this problem is even more evident and, in the case of ER, the situation becomes unavoidable and stressful. Every doctor-patient relationship is based on a common understanding that enables the development of a therapeutic alliance. ${ }^{\text {III }}$

\section{The emergency environment}

When the patient attends a hospital emergency department, he/she has to go through several steps and interact with different individuals. First, the patient is seen by a secretary, who asks him/ her to complete a form with personal information: name, age, health insurance, etc. Second, the patient is questioned and examined by a nurse who evaluates him/her, asks questions, performs certain preliminary tests (temperature, blood pressure, etc.) and determines patient's priority status according to the severity of his/ her condition. Finally, the patient is seen by a physician who will make a diagnosis and propose a treatment plan. The patient has to go through all these steps in a very short period of time and usually has no chance of reporting any relevant information to the different people with whom he/she interacts.

\section{Barriers characteristic of emergency departments}

In an emergency situation, several factors influence the patient-doctor relationship and communication dynamics, e.g. the fact that the patient feels distress, lack of continuum of care, noise, lack of privacy, and scarce time. ${ }^{4}$

\section{Distress}

A medical emergency represents a situation of disturbance of the health status that can rapidly worsen, with or without an intervention. It also represents an actual or potential threat to the patient's life, depending on the severity of the condition. From a symbolic and an emotional perspective, an emergency entails panic, anxiety, distress and helplessness, in short, an unpleasant experience.

\section{Lack of continuum of care}

The ER is just an entry point. If the patient's condition requires medical follow-up, he/ she is transferred to a specialized division. Otherwise, the patient has access to medical care and then is discharged, with or without a medical prescription. It all happens fast and the actors involved change frequently, as mentioned already. Lack of continuum of care represents a barrier to good communication because the different members of the health team usually only read the notes taken at the time the patient is admitted.

\section{Lack of privacy and noise}

Lastly, emergency departments are structured in such a way that the traffic of patients can be smooth and fast. In most emergency rooms the different spaces are open resulting in a lack of privacy. Besides, the background noise in the examination room is continuous and communication is even more difficult.

\section{Time}

Time is required to build a relationship of trust, but emergency situations usually lack such time. Information needs to be collected quickly and for decisions to be made fast, a correct and effective communication is required. The nurse is pressed to obtain as much information as possible regarding the patient's condition in order to estimate its severity and avoid errors during the evaluation that could worsen the patient's status and be potentially life-threatening.

Thus, health care professionals mostly base themselves on their objective and subjective knowledge of the human body to establish

II. Alterity defines the character of what "other" means.

III. The therapeutic alliance (Freud) is the relationship of trust developed between the doctor and the patient. The lack of such alliance could result in misunderstandings, frustration and discontent, which would have serious consequences on the patient's follow-up and healing process. 
whether the patient is in danger. The assessment scale currently in force en Canada establishes a list of specific symptoms in medical terms used by nurses as a guide during the interview.

\section{Communication barriers characteristic of interacting individuals}

However, it should be noted that communication difficulty among the different actors is not only a consequence of the characteristics of the emergency. The socioeconomic context, and the culture and the language of physicians, of the patient and his/her parents play a significant role, probably the most relevant one, in the quality of communication. Through oral interactions, the language of participants helps to define and explain characteristics associated with their ethnic origin, heritage and other elements of their identity.

When there are differences in standards, values, social or professional models between the doctor and his/her patient, the dynamic interaction in the clinical space, the quality of the relationship and the treatment project change. ${ }^{5}$

Understanding, interpretation and reaction to a disease vary according to an individual and his/her cultural roots. To optimize communication with patients, both nurses and physicians need to demonstrate their sensitivity, empathy and listening skills. Communication is therefore essential in the relationship, and verbal communication is the most important.

As shown in several studies, ${ }^{6-10}$ patients have much more difficulty in establishing a trust bond (alliance) with physicians who do not speak their language and often feel that there are misunderstandings or that they can not adequately convey their message. Language in itself is defined as verbal speach with cultural expressions and body language.

What happens when it is not possible to establish verbal communication? When patients do not speak the same language as their doctors, an interpreter or cultural broker in needed.

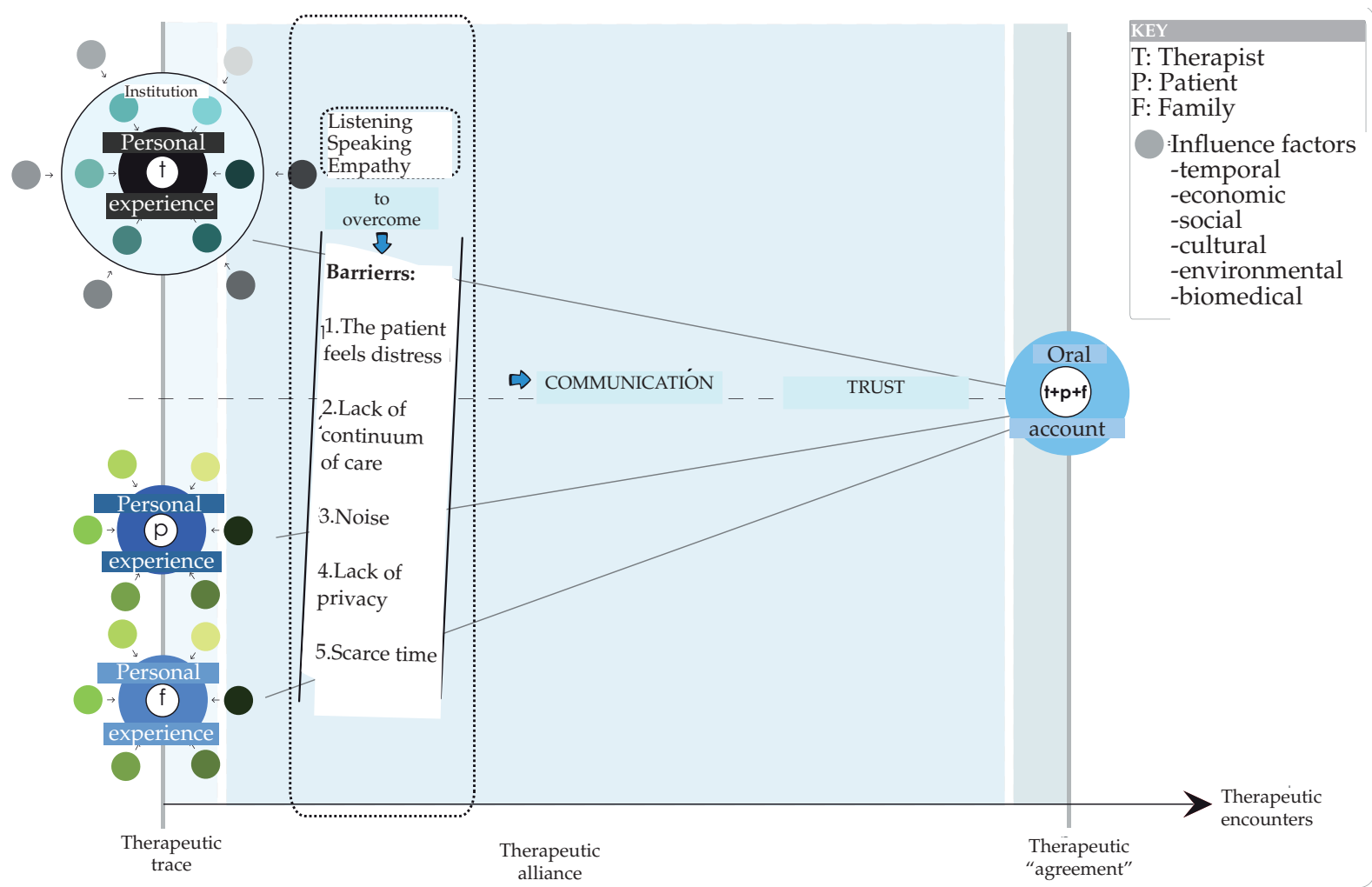


However, in the context of an emergency, health care professionals have neither time nor the resources to get such help.

\section{Solution}

The development of a visual language was presented as an interesting option to overcome barriers in verbal communication. Health care professionals and patients will be able to exchange information using images that represent the message they want to convey. Images propose a common language and a visual aid for communication.

Some anthropologists state that images are an excellent alternative to negotiate reality. Reality should be fictionally represented in order to be approved. ${ }^{11}$ It is not always easy to deal with unpleasant and negative realities. The virtual representation of concepts facilitates the statement of taboos and discomforts. Additionally, the representation implies getting the attention of the subject. ${ }^{12}$ Images should be structured based on design rules, considering technical limitations, in order to create a meaning.

Recognizing an image requires cultural knowledge. However, Cassirer ${ }^{13}$ has clearly explained the power of symbols, ${ }_{,}^{\mathrm{IV}}$ when he stated that all sophisticated and complex cultural forms are ultimately based on primitive and simple forms.

Therefore, there are no classes and subclasses but only an indivisible whole, a continuous set of concepts. An idea can be collective and shared by many people. The construction of a common experience ${ }^{14}$ makes individuals look for meaning using the symbols they share, reproducing them, creating new semantics or incorporating them, ${ }^{15}$ so as to reach a common understanding. This explains how symbols and pictograms are collectively understood and interpreted.

Images are fictional representations of a conceptual reality, and several studies have demonstrated that, when faced with a more realistic representation (holograms, prototypes), people are less sensitive and feel less comfortable with interaction. For this reason, a simple image is required. Besides, in the case of a detailed image, careful reading and time for decoding it are required, which are not necessarily available during an emergency. Therefore, images should be as simple and rational as possible, without rendering it unintelligible.

\section{Challenges}

The challenge posed by the creation of a visual design is how to depict the human body and diseases so that most individuals with different perspectives of the same concept are capable of understanding it. A graphic artist represents what he/she perceives physically and symbolically. References to the body do not have marked cultural variations; all bodies are made up of the same systems and organs.

However, as medical signs and symptoms are not always visible (e.g., nausea), the graphic artist has to use his/her imagination in order to depict them, therefore giving place to a large number of potential interpretations and representations. As a result, the goal is as much as possible to overcome inference so that the image is recognized independently from location, time and the observer. A pictogram or icon (simplified image) should enable an intercultural dialogue.

A scientific investigation about design was conducted with the purpose of establishing an iconographic code that could be recognized by most patients. According to Frascara, ${ }^{16}$ three fundamental elements should be considered when starting a communication design project: ${ }^{v}$ a method, an objective and a mean. So a designer should define the communication methods, the objectives of conveyed messages and the transmission dynamics when establishing the criteria of the design conception to be developed.

The method is design, and it implies an evaluation, reflection, selection and organization process in relation to a series of visual and textual items. The ultimate objective of this method is to generate a clear and effective visual communication. Consequently, the first phase was the study of multicultural and multigenerational pictograms in order to identify the most common iconographic structures used to illustrate symptoms. The study was based on visual culture and semiotics theories. A graphic representation implies the capture of a subject that requires a

IV. Symbols are the graphic representation of an abstract concept.

V. Communication design is a discipline that involves "coordinating a long list of human and technical factors, transforming invisible elements into visible ones, and communicating. "16 Visual or graphic design is differentiated by the inclusion of user experience and interaction in its activities. 
predefined organization procedure. Then images are designed so as to create a meaning, based on codes, which vary in time and space, and according to certain technical limitations.

More than 150 images from different cultures, means of communication and years of publication were analyzed. Descriptions were made in two parts. During the first part, iconographic references were recorded: body description (sex, part of the body, facial expressions, gestures and positions) and contextual elements. During the second part, graphic data were recorded: lines, shapes, colors, contrast and anthropometric proportions. The study of visual culture allowed to identify observation modes, ${ }^{17-29}$ image production and the proposal of an analytic structure and methodology that would help to understand, interpret and explain an image based on denotative and connotative meanings.

The objective is communication. Communication involves the conveyance of a message from the producer of meaning to an interpreter, and gives place to a dialogic dynamics which implies message perception, comprehension, interpretation and validation. Once symbolic systems for medical symptoms were defined, a list of design criteria was determined for the creation of a visual aid. Based on research results, it was possible to identify the predominant trends in the actual "observation mode" and "production mode" of images. Such trends define the symbolic code or design criteria for the graphic representation of symptoms.

At present, the most commonly used communication means for the production and dissemination of medical information are health information and communication technologies (HIT or e-health).

Based on these data, a medical mobile application was developed ${ }^{\mathrm{VI}}$ aimed at reducing communication barriers and allowing patients to express their symptoms during medical emergencies. The visual aid provides medical information through images and works as an alternative to verbal communication. Pictograms and icons represent types of pain, discomfort, injuries, and several types of medications, organized in the same order that nurses follow when asking questions during an emergency, as per the Canadian protocol (Figure 2).

As the nurse or the patient navigate the application and identify symptoms, medical evaluation is described and translated into words. Following the protocol allows patients to avoid missing critical information, and allows nurses to perform a comprehensive questioning: symptoms, pain scale, discomfort, medications, quantity, duration, etc. The application has an easy and intuitive design (Figure 3).

Thanks to such visual aid, nurses are able to shorten the validation process that usually gets hurdled by linguistic differences, collect more information and make an efficient assessment. In turn, it helps patients to express themselves, improve their trust in their physicians and enhance the quality of their medical experience.

\section{DISCUSSION}

\section{Future Research}

As any investigation in design, the last phase is to study the implementation of solutions and the transformations caused by the application. In other words, how would the nurse-patient dynamics change if a visual aid like the one presented here was introduced? Several elements were identified in order to analyze qualitative and quantitative changes. During the second phase, it was important to confirm the proposed hypotheses observed et Sainte-Justine Hospital regarding triage nurses and their patients in terms of:

- time saving during medical evaluation;

- time saving during the patient's journey through the emergency department;

- amount of information collected (more details, avoid overlooking information);

- the quality of patient's comprehension;

- the quality of the doctor-patient relationship;

- the quality of the overall medical experience.

The development of the visual information application was done in collaboration with Jocelyn Gravel, M.D., from Sainte-Justine University Hospital to ensure compliance with the patient screening clinical protocol.

VI. The application can be downloaded from the Canadian or American AppStore under the name "My Symptoms Translator" or "Mon Traducteur de Symptomes." The application can be downloaded for free in French or in English. Web site: http:/ / mysymptomstranslator.ide3s.com 
Several nurses from the same hospital have alredy become familiar with the visual aid and agreed to try it for two months. The objective of this first trial was to confirm if image comprehension and the articulation of linked images were effective. As the doctor and nurse team is already prepared for the use of this type of application; the last stage of implementation will be easier. A methodological protocol has been designed based on observations and focus groups. The hypotheses are based on hermeneutic theories (Gadamer) regarding the recognition and validation of received information.
Plausible implementation in other hospital divisions

We chose to initially study the situation in the emergency room as a long-term strategy.

The introduction of a visual aid such as "My Symptoms Translator" in hospital emergency departments allows us to reach a greater number of patients with different, sometimes complex, symptoms, and to try our concept in a context where there are no other means of visual communication. If our application is approved in a specific situation, it will be easier to transfer our knowledge to other hospital divisions.

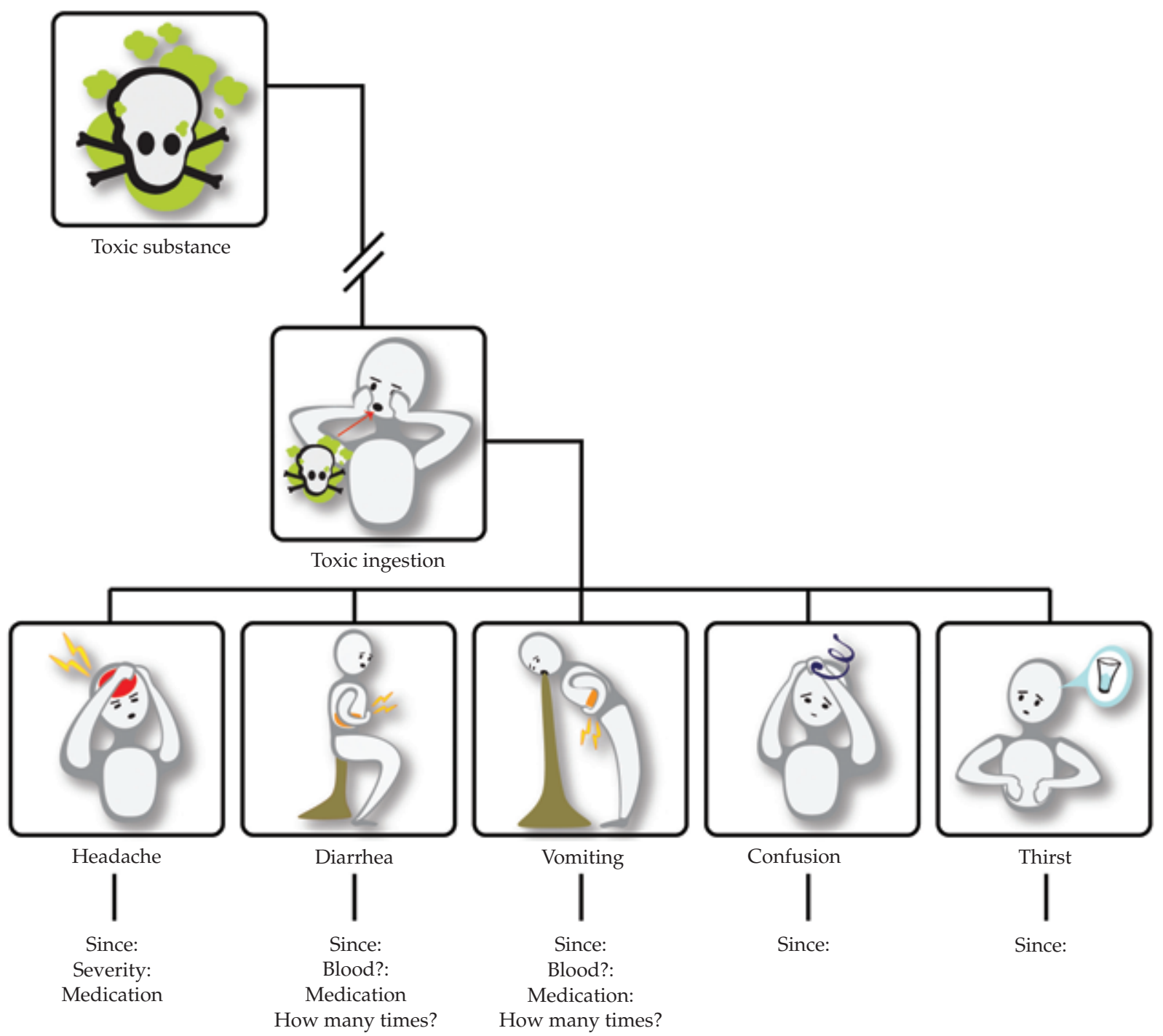




\section{REFERENCES}

1. Gauthier A, Alvarez F, Bibean G, Tapiero B, Turgeon J. Émergence d' une pédiatrie interculturelle a l'Hopital Sainte Justine: penser la pluralité sociale et culturelle des familles. In: De Plaen S. Soins aux enfants et pluralisme culturel, Montréal: Éditions de 1' Hopital Sainte Justine; 2004. Pág.15-16.

2. Sachs-Jeantet C. La citoyenneté, projet de civilisation urbaine, Un autre partage: homme, ville, nature. Eres et UNESCO; 1993.Pág.173-198.

3. Giordan H. Les sociétés pluriculturelles et pluriethniques. Paris: MOST Documents de discussion (no.1): UNESCO; 1994.

4. Crane JA. Patient comprehension of doctor-patient communication on discharge from the Emergency department. J Emerg Med 1997;15(1):1-7.

5. Bibeau G. Une troisieme voie en santé publique, Rupture. Revuetrans disciplinaire en santé. 1999;6(no.2).

6. Carrasquillo O, Orav J. Impact of language barriers on patient satisfaction in a Emergency room. J Gen Int Med 1999;14:82-7.

7. Ferguson WJ, Candib LM. Culture, language and the doctor-patient relationship, Familiy Medecine 2002;34(5):353-61.

8. Miller AR, Brown JM, Cullen CD. Global graphics: symbols. Massachusetts: Rockport publishers; 2000. Pág.191.
9. Karliner LS, Perez-Stable EL. The language divide: the importance of training in the use of interpreters for outpatient practice. J Gen Int Med 2004;19:175-83.

10. Squires A. Language barriers and qualitative nursing research: methodological considerations. Int Nur Rev 2008;55:265-73.

11. Simonis Y. Pouvoirs de l'image. Anthropol Soc 1992;16(1): 7-20.

12. Letendre P. L' image de ce qui ne peut étre vu. Anthropol Soc 1992;16(1):81-90.

13. Cassirer E. Philosophie des formes symboliques. Tome 3. Paris: Minuit; 1923. Pág.29.

14. Laing RD. The politics of experience. Hamonds worth: Penguin Books; 1967.Pág.190.

15. Fernández JW. The argument of images and the experience of return in to the whole. En: Turner VM, Bruner EM. The anthropology of experience. Etats-Unis: University of Illinois; 1986. Pág.160.

16. Frascara J. El diseño de la comunicación. Buenos Aires: Ediciones Infinito; 2006. Pág.172.

17. Alpers S. El arte de describir. El arte holandés en el siglo XVII. Madrid: Hermann Blume; 1987. Chicago: The University of Chicago; 1983.

18. Baxandall M. Introducción y el ojo de la época, pintura y

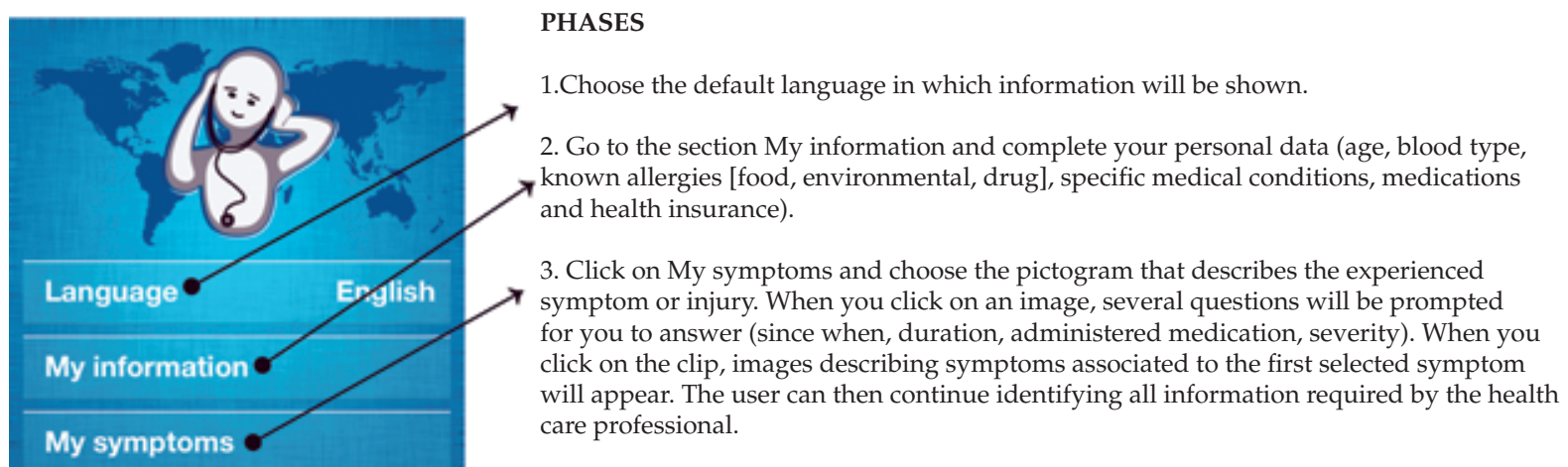
Related questions $\longrightarrow$ (Did you use illegal drugs?, Did you eat local food?, Did you drink tap water?, Did you have unprotected sexual intercourse?, etc.)

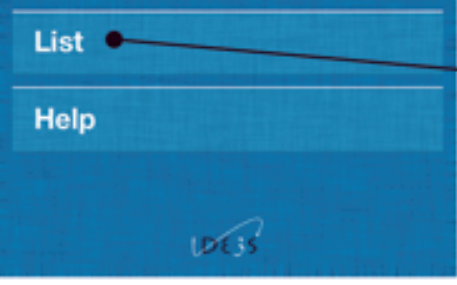

5. Click on the list icon (down to the right) to obtain all information entered by the user. The list is accompanied with images.

6. Click on the translation icon (down to the right) and choose the language spoken by the nurse or doctor.

7. The health care professional can go through the same navigation process in order to ask questions to the patient using, in turn, the adequate pictograms and icons.
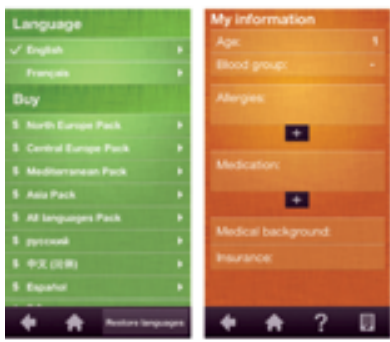

1.

2.

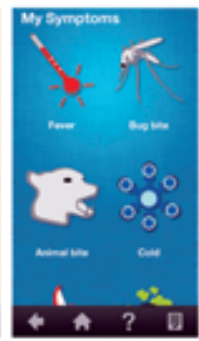

3.
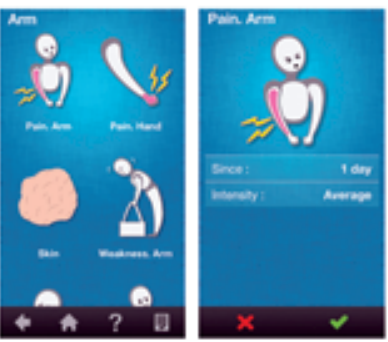

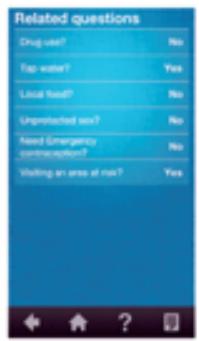

4.

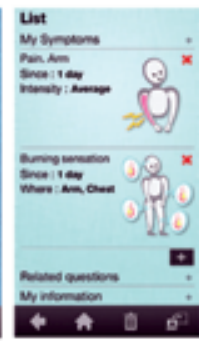

s.

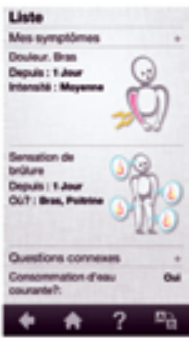

6. 
vida cotidiana en el Renacimiento. Arte y experiencia en el Quattrocento. Barcelone: Ed. Gustavo Gili; 1978. NewYork: Oxford University Press; 1972.

19. Benjamin W. Discursos interrumpidos I. Filosofía del arte y la historia. Buenos Aires: Editorial Taurus; 1989.

20. Benjamin W. Escritor revolucionario. Buenos Aires: Interzona; 2005.

21. Berger J. Modos de ver. Barcelona: Ed. Gustavo Gili; 1980. Londres: Penguin Books; 1974.

22. Stoichita V. Ver y no ver. Madrid: Siruela; 2005.

23. Robins K. ¿Nos seguirá conmoviendo una fotografía? En: Lister M. La imagen fotográfica en la cultura digital. Barcelona: Paidós; 1997. Pág.336.

24. Quéau P. La puissance des images. Anthropologie et Sociétés 1192;16(1):91-4.
25. Mitchell J. Mostrando el ver. Una crítica a la cultura visual, Revista de Estudios Visuales, no 1, Barcelona: CENDEAL;2003.

26. Appadurai A. Modernity at Large: Cultural Dimensions of Globalization. Minneapolis London: University of Minnesota Press; 2000.

27. Veron E. Discursos sociales et El sentido como producción discursiva, La semiosis social. Fragmentos de una teoría de la discursividad. Buenos Aires: Gedisa; 1987.

28. Veron E. Pour en finir avec la communication. Réseaux 1991; 9(46):119-26.

29. Veron E. Cuando leer es hacer: la enunciación en la prensa gráfica y Diccionario de lugares no comunes, Fragmentos de un tejido. Buenos Aires: Gedisa; 2004. 